\title{
A EDUCAÇÃO AMBIENTAL NAS ESCOLAS DE SANTA CATARINA
}

\author{
Jose Cláudio Ramos Rodrigues ${ }^{1}$
}

\begin{abstract}
RESUMO
O presente artigo se propõe a refletir sobre a importância da educação ambiental e sua emergência nos níveis internacional e nacional discutindo, especialmente, os contextos e as principais políticas públicas que foram responsáveis pela consolidação e institucionalização da educação ambiental em Santa Catarina. Apresenta ainda um panorama e uma breve análise da educação ambiental praticada nas escolas de Santa Catarina, a partir das informações obtidas na pesquisa do MEC intitulada "O que fazem as escolas que dizem que fazem Educação Ambiental?", realizada em 2006 e publicada em 2007, e dos registros do I, II e III Encontro Catarinense de Educação Ambiental - ECEA, ocorridos nos anos de 2011, 2012 e 2014, respectivamente.
\end{abstract}

Palavras-chave: Educação Ambiental. Santa Catarina. Escola.

\begin{abstract}
This article aims to reflect on the importance of environmental education and its emergence on the international and national levels. It discusses especially the contexts and the main public policies that were responsible for the consolidation and institutionalization of environmental education in Santa Catarina. Also it presents an overview and a brief analysis of environmental education practiced in the schools of Santa Catarina, from the information obtained in the survey conducted by MEC entitled "What do the schools that say they do environmental education?", held in 2006 and published in 2007, also the records of the I, II and III of Santa Catarina Meeting of Environmental Education - ECAA, which occurred in 2011, 2012 and 2014, respectively.
\end{abstract}

Keywords: Environmental Education. Santa Catarina. School.

\footnotetext{
${ }^{1}$ Mestre em Engenharia de Produção com Ênfase em Gestão Ambiental - UFSC. Doutorando do Programa de Pós Graduação em Geografia - UFSC. Professor titular do Ensino Básico Técnico e Tecnológico do Instituto Federal de Educação, Ciência e Tecnologia Catarinense Campus Santa Rosa do Sul.
} 
AMBIENTE \& EDUCAÇÃO

ISSN- 1413-8638

E-ISSN - 2238-5533

v. 23, n. 1, p. $140-160,2018$

\section{Introdução}

Alguns fatores, como o acelerado crescimento populacional humano, a revolução industrial e o desenvolvimento científico e tecnológico das últimas décadas, contribuíram para o agravamento da chamada crise ambiental, que adquiriu relevância social especialmente a partir das décadas de 1960 e 1970. Diante da diversidade e da gravidade dos problemas ambientais, a sociedade viu-se obrigada a refletir e a discutir sobre suas causas e consequências, a questionar os modelos de desenvolvimento econômico adotados, os padrões de produção e consumo, enfim, as relações entre sociedade e natureza.

A educação ambiental surge, no início da década de 1970, como uma estratégia e ao mesmo tempo uma esperança para reverter o atual processo de degradação socioambiental, que pela primeira vez ameaça a continuidade da vida no planeta. Sua trajetória é marcada pela identidade de princípios e diretrizes que a acompanham desde a sua origem, mas também pela diversidade de discursos e concepções que the conferem o dinamismo e a vivacidade de um campo em constante disputa.

A educação ambiental não é uma atividade recente no Brasil. Pedrini (2008) comenta que antes da Conferência de Estocolmo já era citada em uma concepção ampla, como educação conservacionista, ecológica, sanitária e florestal, chegando a ser mencionada em 1948 em documento oficial ${ }^{2}$ com caráter restritivo à dimensão ecológica.

De acordo com Carvalho (2008), a educação ambiental surge como uma resposta da educação às preocupações da sociedade com as questões ambientais e, portanto, não pode ser totalmente compreendida sem levar em consideração as contribuições dos movimentos ecológicos. Ainda segundo a autora, os resultados e desdobramentos das grandes conferências sobre as questões ambientais no plano internacional influenciaram tanto a origem quanto a institucionalização da educação ambiental no Brasil.

Porém, tratando-se da institucionalização da educação ambiental no Brasil, no plano governamental, segundo Lima (2011), temos a Secretaria Especial do Meio Ambiente (SEMA), criada em 1973 pelo presidente da

\footnotetext{
${ }^{2}$ Decreto legislativo federal 3, de 13 de fevereiro de 1948, que aprovava a Convenção para a Proteção da Flora, Fauna e Belezas Cênicas Naturais dos Países da América (FBCN/Cesp, 1986).
} 
república no âmbito do Ministério do Interior. Trata-se do primeiro organismo brasileiro voltado para a gestão integrada do ambiente, incluindo o desenvolvimento da educação ambiental.

Desde então, diversas políticas públicas implementadas pelos governos que se sucederam foram responsáveis pela consolidação da educação ambiental no Brasil, com destaque para a Lei no 6.939, de 1981, que criou a Política Nacional do Meio Ambiente (PNMA), responsável, segundo Pedrini (2008), pela instituição formal da educação ambiental no Brasil. Outro destaque

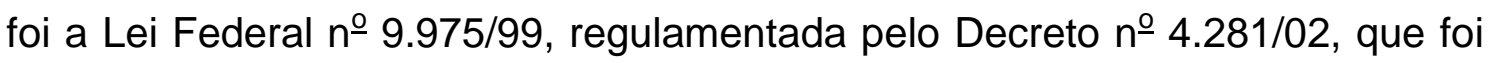
o grande marco da educação ambiental por reconhecê-la como um componente essencial e permanente da educação nacional, recomendando a sua presença de forma articulada, em todos os níveis e modalidades do processo educativo, em caráter formal e não formal.

\section{A educação ambiental em Santa Catarina}

A educação ambiental em Santa Catarina, no âmbito de processos educativos não formais, conta com importantes instituições e entidades que desde a década de 1980 desenvolvem relevantes atividades de educação ambiental e proteção e uso sustentável dos recursos naturais. Entre as diversas entidades cabe destacar aquelas que compõem o colegiado da Comissão Interinstitucional de Educação Ambiental do Estado de Santa Catarina - CIEA/SC (SANTA CATARINA, 2010), que são: o Instituto Larus, que iniciou suas atividades ainda no início da década de 1980 e até hoje busca disseminar o conhecimento sobre a natureza, com ênfase nos ambientes marinhos, promovendo e realizando ações de pesquisa, proteção e educação ambiental (LARUS, 2015); a Federação de Entidades Ecologistas Catarinenses (FEEC), que foi fundada em 1988 e coordena as atividades de diversas organizações não governamentais associadas (MATER NATURA, 2015); e a Rede Sul Brasileira de Educação Ambiental - REASul, formada em 2002 por pesquisadores de duas universidades (Univali e FURG), ambientalistas de uma ONG (Mater Natura) e gestores de políticas públicas do Ibama. A REASul atua nos três estados da região sul do Brasil e desenvolve ações que visam fortalecer a comunicação entre educadores, educadoras e outros profissionais 
envolvidos com o compromisso da inserção da dimensão socioambiental nas práticas educativas e sociais e a difusão dos objetivos e princípios da educação ambiental (SANTA CATARINA, 2015a).

Refletindo o processo tardio de consolidação da educação ambiental como política pública em nível nacional, percebe-se que a educação ambiental em Santa Catarina, no processo educativo de âmbito formal, também teve sua inserção tardiamente. A educação ambiental passou a compor formalmente 0 currículo na década de 1990, com a formulação da Proposta Curricular de Santa Catarina (PC/SC), e a criação dos instrumentos legais que permitiram a sua estruturação e consolidação se deu apenas a partir do ano 2000.

A formulação da Proposta Curricular do Estado de Santa Catarina ocorreu, segundo Santa Catarina (1998), num contexto de redemocratização política do Brasil, a partir de 1985, quando se inicia um movimento de discussão que provocou um repensar da educação brasileira. Reflexões e discussões sobre questões curriculares levaram à introdução de um referencial teórico identificado com o pensamento histórico-cultural no cenário da educação básica, incluindo autores como Antonio Gramsci.

Os diversos documentos publicados que constituem a Proposta Curricular de Santa Catarina são resultado de uma construção coletiva de educadores, cujo processo teve início em 1988, com a sua primeira publicação em 1991. A partir daí essa proposta vem sendo objeto de discussões, visando ao aprofundamento de seus pressupostos teórico-metodológicos e à sua atualização e consolidação na prática pedagógica.

A segunda versão da PC foi publicada em 1998 e constitui-se de três volumes: Disciplinas Curriculares, Temas Multidisciplinares e Formação Docente, reunindo, portanto, em volumes separados, textos referentes às disciplinas curriculares, aos conteúdos de abrangência multidisciplinar e ao curso de Magistério.

A educação ambiental integra o documento Temas Multidisciplinares sendo concebida em uma visão ampla, integrando os aspectos ambientais e sociais, conforme pode se constatar na função a ela atribuída de "[...] contribuir para a formação de cidadãos conscientes e críticos, capazes para decidirem e atuarem na realidade socioambiental de um modo comprometido com a vida, 
com o bem-estar de cada um e da sociedade [...]" (SANTA CATARINA, 1998, p. 42). A educação ambiental é entendida ainda de forma processual, sendo recomendada a sua integração na educação como

[...] um tema transversal que permeia os diferentes conteúdos disciplinares e envolve a apropriação de conteúdos, formação de conceitos e a aquisição de competências para agir na realidade de forma transformadora. (SANTA CATARINA, 1998, p. 47).

O documento apresenta a educação ambiental inscrita em uma orientação pedagógica histórico-crítica que também orienta toda a proposta curricular. No entanto, segundo a PC, tal orientação não exclui a possibilidade de incorporar a contribuição de novos conceitos e abordagens que emergem da própria evolução da educação ambiental, como a abordagem sistêmica e o pensamento complexo, a fim de que esta não se torne ultrapassada e possa cumprir com seus objetivos.

Ainda com relação aos aspectos metodológicos da educação ambiental, a PC orienta para a inserção da temática socioambiental nas disciplinas, contextualizando historicamente os problemas, considerando o ser humano como um ser social concreto, que interage com a natureza pelas relações histórico-culturais estabelecidas (DAHMER, 2014). Também comentando sobre o viés metodológico da PC de Santa Catarina, Nascimento (2003, p. 59) afirma que

[...] as diretrizes são norteadas por uma metodologia problematizadora, que visa a permitir a leitura crítica e reflexiva do ambiente em que os alunos estão inseridos, sem perder de vista a produção de conhecimentos abertos e não limitados, que possibilitem uma visão ampla da realidade, das questões ambientais, das causas reais, das potencialidades alternativas e possíveis soluções a serem implementadas pelos envolvidos, e da responsabilidade individual e coletiva dos atores que as formam.

Mesmo entendendo a complexidade de se propor uma metodologia para a educação ambiental, conforme se pode perceber, o documento não se exime de apresentar algumas diretrizes ou propostas de ordem genérica, entre as quais se destacam a metodologia problematizadora e o trabalho com projetos. Observa-se ainda a ênfase para a importância de se partir da leitura crítica e reflexiva do ambiente próximo do aluno, sem perder de vista todas as 
dimensões da educação ambiental, ou seja, os aspectos históricos, políticos, econômicos, sociais e culturais subjacentes aos temas trabalhados. Enfatiza-se também a importância de se buscar formas de contribuir para a solução dos problemas ambientais identificados, bem como de se fazer as devidas conexões e relações dos problemas locais com as realidades regionais, nacionais e internacionais.

\section{Os marcos legais e a institucionalização da educação ambiental em Santa}

\section{Catarina}

A criação dos marcos legais e a formulação de políticas públicas que possibilitaram o enraizamento e a consolidação da educação ambiental em Santa Catarina ocorrem a partir dos anos 2000, conforme se pode observar nas descrições a seguir.

A Comissão Interinstitucional de Educação Ambiental do Estado de Santa Catarina (CIEA-SC) foi instituída em 2001, por meio do Decreto nํ2 2489, sofrendo alterações posteriores pelos Decretos $n^{\circ} 3.214 / 2001$ e $n^{\circ}$ 1.288/2003 (BRASIL, 2006). De acordo com a Secretaria de Estado do Desenvolvimento Econômico Sustentável de Santa Catarina (SANTA CATARINA, 2015b), levando-se em consideração as Recomendações da $1^{\text {a }}$ Conferência Intergovernamental sobre Educação Ambiental de Tbilisi, de 1977, e buscando a sintonia com a Política Nacional de Educação Ambiental (PNEA), essa comissão tem por finalidade identificar, analisar e propor ações e processos participativos na construção e no acompanhamento de políticas e programas de Educação Ambiental no Estado.

Conforme Artigo $3^{0}$ do seu regimento interno, a CIEA/SC tem a sua estrutura composta por: colegiado, coordenação geral, secretaria executiva, subcomissões e grupos de trabalho. No entanto, a CIEA/SC começou suas ações efetivamente a partir de 2004 (BRASIL, 2006), com a renovação e inclusão de novas instituições para compor o colegiado e a formação de quatro grupos de trabalho: Polos, Políticas Públicas, Eventos Coletivos e Análise de Projetos. É importante ressaltar que as instituições que participam da CIEA têm sido parceiras e se envolvido de alguma forma em programas do Órgão Gestor, tornando possível unir os movimentos da educação ambiental pulverizados nas 
diversas regiões. Em 2006, o GT de Políticas Públicas, constituído no âmbito da CIEA, elaborou o Programa Estadual de Educação Ambiental (ProEEA).

Cabe destacar brevemente que em junho de 2000 teve início o processo de construção da Agenda 21 catarinense, cuja conclusão e publicação ocorreram em outubro de 2002. Na seção sobre Meio Ambiente, a educação ambiental é apontada como uma das estratégias para promover a sustentabilidade ambiental e aparece como uma proposta que sugere "Implantar a educação ambiental formal e não formal, dando atenção a conteúdos sobre os ecossistemas catarinenses" (SANTA CATARINA, 2004, p. 92).

Por fim, cabe destacar que a Política Estadual de Educação Ambiental do Estado de Santa Catarina (PEEA/SC) foi instituída pela Lei nํㅜ 13.558, de 17 de novembro de 2005, e o Programa Estadual de Educação Ambiental de Santa Catarina (ProEEA/SC), previsto na referida lei, foi regulamentado pelo Decreto $n \underline{0}$ 3.726, de 14 de dezembro de 2010 .

\section{A educação ambiental praticada nas escolas de Santa Catarina}

Pela escassez de informações, pouco se sabe a respeito das atividades de educação ambiental desenvolvidas nas escolas de Santa Catarina, uma vez que não há documentos oficiais que forneçam informações que permitam traçar um panorama sobre essa realidade em nível estadual. Assim, visando apresentar, mesmo que de forma sucinta, algumas informações sobre o tema, foram utilizadas duas fontes básicas de pesquisa: os dados da pesquisa realizada pelo MEC intitulada "O que fazem as escolas que dizem que fazem Educação Ambiental?", realizada em 2006 e publicada em 2007, e os registros do I, II e III Encontro Catarinense de Educação Ambiental - ECEA, ocorridos nos anos de 2011, 2012 e 2014, respectivamente.

A pesquisa do MEC "O que fazem as escolas que dizem que fazem Educação Ambiental?" (BRASIL, 2007) foi desenvolvida pela CoordenaçãoGeral de Educação Ambiental em parceria entre o Instituto de Estudos do Trabalho e Sociedade (IETS) e as universidades federais do Rio Grande (FURG), Mato Grosso do Sul (UFMS), Rio de Janeiro (UFRJ), Rio Grande do Norte (UFRN) e Pará (UFPA). A pesquisa teve como objetivo adquirir 
conhecimento e prover insumos para o aperfeiçoamento de políticas e programas na área da Educação Ambiental nas escolas de ensino fundamental do País. Na pesquisa 418 escolas foram entrevistadas nas cinco regiões do Brasil. Na região Sul foram selecionados para fazer parte da pesquisa os Estados de Santa Catarina e do Rio Grande do Sul - a escolha do Estado do Rio Grande do Sul se deve ao fato de ser sede de uma das instituições parceiras da pesquisa (FURG) e a escolha do Estado de Santa Catarina pelo reconhecimento de implementações de Políticas Públicas de Gestão em Educação Ambiental.

No Estado de Santa Catarina foram selecionados os municípios de Florianópolis, por ser a capital do Estado (um dos critérios estipulados pela pesquisa), Joinville, Jaraguá do Sul e Itajaí, devido a suas colocações no Índice de Desenvolvimento em Educação Ambiental - IDEEA ${ }^{3}$. No Estado de Santa Catarina foi entrevistado um total de 40 escolas, sendo 10 em cada um dos municípios selecionados (BRASIL, 2007).

Como a pesquisa e os dados são geralmente apresentados e analisados por região, serão apresentados a seguir apenas os dados e análises referentes ao Estado de Santa Catarina, foco deste artigo.

A pesquisa procurou saber há quanto tempo as escolas desenvolvem a Educação Ambiental e qual o fator inicial que as motivou. Assim, a tabela 1 apresenta um cruzamento de dados entre o tempo em que a escola desenvolve Educação Ambiental e a sua motivação inicial para trabalhar com essa temática.

\footnotetext{
${ }^{3}$ O Índice de Desenvolvimento em Educação Ambiental - IDEA é um índice sintético construído com o propósito de mensurar de forma um pouco mais acurada os avanços da Educação Ambiental nas escolas. O IDEA é composto por três grandes dimensões que abarcam 19 indicadores. A primeira dimensão é denominada de Educação Ambiental, e esta por sua vez está dividida em duas subdimensões: acesso à Educação Ambiental e índice de diversificação das modalidades da Educação Ambiental (BRASIL, 2007).
} 
Tabela 1 - Tempo em que a escola desenvolve EA e motivação inicial para trabalhar com ela nas escolas de Santa Catarina - 2006

\begin{tabular}{l|c|c|c|c|c|c}
\hline $\begin{array}{l}\text { Motivações/tempo } \\
\text { em que desenvolve a EA }\end{array}$ & $\begin{array}{c}\text { Menos } \\
\text { de 1 } \\
\text { ano }\end{array}$ & $\begin{array}{c}\text { De 1 a } \\
\text { anos }\end{array}$ & $\begin{array}{c}\text { De 3 a } \\
\mathbf{7} \text { anos }\end{array}$ & $\begin{array}{c}\text { De 7 a } \\
\mathbf{9} \text { anos }\end{array}$ & $\begin{array}{c}\text { De 9 a } \\
\mathbf{1 0} \\
\text { anos }\end{array}$ & $\begin{array}{c}\text { Mais } \\
\text { de 10 } \\
\text { anos }\end{array}$ \\
\hline $\begin{array}{l}\text { Conf. } \\
\text { Infantojuvenil para o M.A. }\end{array}$ & 0 & 5 & 2 & 0 & 0 & 1 \\
$\begin{array}{l}\text { Diretriz da Secretaria Estad. } \\
\text { Mun. de Educação }\end{array}$ & 0 & 3 & 3 & 0 & 2 & 5 \\
$\begin{array}{l}\text { Iniciativa de um professor } \\
\text { ou grupo de professores }\end{array}$ & 0 & 5 & 6 & 1 & 1 & 12 \\
$\begin{array}{l}\text { Interesse dos alunos } \\
\text { Notícias vinculadas na } \\
\text { mídia }\end{array}$ & 0 & 0 & 2 & 1 & 0 & 3 \\
$\begin{array}{l}\text { Parâmetros em ação: meio } \\
\text { ambiente na escola }\end{array}$ & 0 & 0 & 2 & 1 & 1 & 7 \\
$\begin{array}{l}\text { Políticas Programas } \\
\text { Nacional e Estadual de EA }\end{array}$ & 0 & 1 & 1 & 0 & 1 & 3 \\
Problema Ambiental na \\
escola
\end{tabular}

Fonte: Projeto "O que fazem as escolas que dizem que fazem Educação Ambiental" (BRASIL, 2007), adaptado por Rodrigues, 2015.

De acordo com análise da pesquisa, sobre o tempo em que a escola desenvolve Educação Ambiental, relacionado com a motivação inicial para trabalhar com essa temática, é possível analisar que, provocadas pela Conferência Nacional Infantojuvenil para o Meio Ambiente, cinco escolas de Santa Catarina afirmam desenvolver de um a três anos. Em relação à Diretriz da Secretaria Estadual/Municipal de Educação como motivação para a Educação Ambiental, três escolas de Santa Catarina desenvolvem a EA de um a três anos, apenas uma escola desenvolve de sete a nove anos e cinco escolas no Estado declararam desenvolver a Educação Ambiental há mais de dez anos. Observa-se que, com a Iniciativa de um professor ou grupo de professores, 12 escolas em Santa Catarina afirmam desenvolver a Educação Ambiental motivadas por essa iniciativa (BRASIL, 2007).

No que se refere ao modo como a escola desenvolve a Educação Ambiental, os dados são apresentados na tabela 2 a seguir. 
Tabela 2 - Modalidades de educação ambiental nas escolas de Santa Catarina $-2006$

\begin{tabular}{l|c}
\hline \multicolumn{1}{c|}{ Modalidades } & Número de escolas \\
\hline Atividades comunitárias & 2 \\
Datas e eventos comemorativos & 9 \\
Inserção no projeto político-pedagógico & 21 \\
Inserção da temática em disciplinas específicas & 10 \\
Tema transversal & 11 \\
Projetos & 27 \\
Disciplina especial & 1 \\
\hline
\end{tabular}

Fonte: Projeto "O que fazem as escolas que dizem que fazem Educação Ambiental" (BRASIL, 2007), adaptado por Rodrigues, 2015.

A análise da pesquisa destaca a ênfase dos projetos nas escolas e também ressalta a força da inserção da Educação Ambiental no projeto político-pedagógico, porém afirma que tais dados permitem algumas indagações quando se leva em conta "[...] a motivação inicial que se encontra expressivamente na iniciativa de um professor ou grupo de professores. Assim, pode-se dizer que houve uma transformação no modo de desenvolver a Educação Ambiental nas escolas" (BRASIL, 2007, p. 219).

A pesquisa também procurou investigar quais as principais dificuldades encontradas pelas escolas para o desenvolvimento da Educação Ambiental, e os resultados referentes ao Estado de Santa Catarina são apresentados na tabela 3 a seguir.

Tabela 3 - Principais dificuldades enfrentadas no desenvolvimento da EA nas escolas de Santa Catarina - 2006

\begin{tabular}{l|c}
\hline \multicolumn{1}{c|}{ Principais dificuldades } & Número de escolas \\
\hline Conflito de interesses & 2 \\
Falta de tempo para o planejamento e realização de \\
atividades extracurriculares
\end{tabular}


A análise da pesquisa destaca que a falta de tempo é o maior obstáculo para a realização da Educação Ambiental nas escolas. Tal índice, segundo análise, indica a necessidade urgente de rediscutir as diretrizes educacionais da escola representadas no seu projeto político-pedagógico, para realmente propiciarem a inserção da temática. Indica ainda a necessidade da formulação e implementação de políticas públicas para promover a estruturação e organização da Educação Ambiental nas escolas (BRASIL, 2007).

Os Encontros Catarinenses de Educação Ambiental (ECEA) originaram de diversas reuniões e encontros para discussão e troca de ideias, coordenados pela Comissão Interinstitucional de Educação Ambiental do Estado de Santa Catarina - CIEA-SC (SANTA CATARINA, 2015c). As duas primeiras edições do encontro reuniram aproximadamente 900 educadores ambientais do Estado e do Brasil (os números dos participantes do terceiro e último encontro, realizado em 2014, ainda não foram disponibilizados).

Devido à limitação das informações contidas nos registros desses encontros, não é possível apresentar um panorama detalhado das atividades de educação ambiental desenvolvidas nas escolas de Santa Catarina. Assim, serão apresentadas algumas informações principalmente sobre a temática dessas atividades e também sobre a sua natureza ou formas de realização, quando estiverem disponíveis. Além dos anais dos encontros e outras informações, também se utilizou como fonte de pesquisa a monografia intitulada "Educação Ambiental e Políticas Públicas em Santa Catarina: os casos dos I e II Encontros Catarinenses de Educação Ambiental”, publicada em 2013 por Marli Carvalho de Araújo.

O I ECEA foi realizado nos dias 20 e 21 de setembro de 2011 na Assembleia Legislativa do Estado de Santa Catarina (ALESC), em Florianópolis. Os interessados em participar do encontro poderiam se inscrever para apresentação de pôster, enviando os resumos para um endereço eletrônico disponibilizado nos materiais de divulgação do evento (ARAÚJO, 2013). Ao inscrever o seu resumo, cada participante deveria indicar a qual eixo temático do Programa Estadual de Educação Ambiental ele está sendo submetido, de um total de sete: I - formação de recursos humanos para educação ambiental; II - desenvolvimento de estudos, pesquisas e 
experimentações; III - produção e divulgação de material educativo; IV acompanhamento e avaliação continuada; V - disponibilização permanente de informações; VI - integração através da cultura de redes sociais; e VII - busca de fontes de recursos.

De um total de 106 resumos inscritos no I ECEA, a distribuição nos eixos temáticos ocorreu da seguinte forma: eixo I, 20 trabalhos; eixo II, 62; eixo III, 12; eixo IV, um trabalho; eixo V, oito; eixo VI, três; e eixo VII, nenhum trabalho inscrito (ARAÚJO, 2013). Observa-se que houve maior volume de resumos inscritos no eixo II, que trata do desenvolvimento de estudos, pesquisas e experimentações de educação ambiental desenvolvidas nos mais diversos espaços, entre eles as escolas. Do total dos 62 trabalhos inscritos nesse eixo, identificaram-se 28 que se referem a atividades de educação ambiental no ensino formal, envolvendo os alunos.

Assim, com base em Araújo (2013), serão apresentados na tabela 4 a seguir os temas referentes aos 28 resumos inscritos no eixo II, relacionado a atividades de educação ambiental desenvolvidas nas escolas.

Tabela 4 - Temas das atividades de EA desenvolvidas nas escolas apresentadas no I ECEA/2011

\begin{tabular}{l|c}
\hline \multicolumn{1}{c|}{ Tema } & Quantidade \\
\hline Lixo, resíduos - 5 Rs & 8 \\
Horta escolar, jardinagem e plantio de árvores & 8 \\
EA em ambientes naturais como rios e matas - passeios e trilhas & 5 \\
EA desenvolvida em uma única disciplina & 2 \\
\hline Temas não identificados & 2 \\
\hline Curso de EA para alunos & 1 \\
Projeto de EA em parceria com empresas & 1 \\
Projeto em um rio envolvendo aspectos físicos (água) e culturais & 1 \\
(população ribeirinha) & $\mathbf{2 8}$ \\
\hline Total &
\end{tabular}

Fonte: Araújo (2013) adaptado por Rodrigues, 2015

Chama a atenção o grande número de atividades envolvendo a temática lixo e a temática hortas escolares e jardinagem, que, apesar da escassez de informações disponíveis, foram desenvolvidas de diversas formas e com objetivos igualmente diversos. No caso da temática lixo as atividades normalmente envolvem coleta seletiva, reciclagem ou reutilização. Já a 
temática hortas escolares e jardinagem geralmente envolve a compostagem de resíduos orgânicos gerados na escola para utilização como fertilizante natural.

É importante destacar também o grande número de passeios e trilhas em ambientes naturais. Essas atividades, entre outros aspectos, têm o mérito de envolver e integrar os alunos com o seu entorno, porém há o risco de reduzir a educação ambiental aos seus aspectos apenas físicos, biológicos ou naturais, desconsiderando-se os demais. É interessante destacar ainda um projeto de educação ambiental desenvolvido em parceria com uma empresa. De acordo com as macrotendências político-pedagógicas da educação ambiental brasileira abordadas por Layrargues e Lima (2011) e Layrargues (2012), esse modelo de educação ambiental filia-se à macrotendência pragmática e às correntes de educação ambiental para o desenvolvimento sustentável e para o consumo sustentável. Já o desenvolvimento de um projeto em um rio integrando aspectos físicos e sociais desse ambiente indica claramente uma filiação à macrotendência crítica de educação ambiental, segundo os mesmos autores.

O II ECEA foi realizado nos dias 29 e 30 de outubro de 2012 no Teatro Governador Pedro Ivo Campos, em Florianópolis, e um de seus objetivos foi identificar o que vem sendo desenvolvido a partir dos dois primeiros eixos do ProEEA/SC: eixo I - Formação de Recursos Humanos para Educação Ambiental, e eixo II - Desenvolvimento de Estudos, Pesquisas e Experimentações (ARAÚJO, 2013).

Ainda segundo a autora, o II ECEA teve um total de 72 resumos inscritos, que ficaram assim distribuídos em cada eixo temático: eixo I, 12 trabalhos; eixo II, 55; eixo III dois e eixo VI três trabalhos. Não houve resumos inscritos nos eixos temáticos IV, V e VII. Observa-se novamente um maior volume de resumos inscritos no eixo II, com um total de 55 trabalhos inscritos, sendo 23 referentes a atividades de estudos, pesquisas e experimentações desenvolvidas no âmbito formal de ensino, envolvendo os alunos.

Assim, com base em Araújo (2013) serão apresentados na tabela 5 a seguir os temas dos 23 resumos inscritos no eixo II que se referem a atividades de educação ambiental desenvolvidas nas escolas. 
Tabela 5 - Temas das atividades de EA desenvolvidas nas escolas e apresentadas no II ECEA/2012

\begin{tabular}{l|c}
\hline \multicolumn{1}{c|}{ Tema } & Quantidade \\
\hline EA em áreas protegidas (UCs) e áreas naturais - passeios e trilhas & 9 \\
Lixo - coleta seletiva, reciclagem, reutilização e compostagem & 6 \\
Curso de EA ou abordagem expositiva & 2 \\
Viveiros educadores na escola & 1 \\
Arborização urbana & 1 \\
\hline Gincana ambiental & 1 \\
EA e alimentação dos alunos & 1 \\
EA em uma única disciplina & 1 \\
Tema não identificado & 1 \\
Total & $\mathbf{2 3}$ \\
\hline
\end{tabular}

Fonte: Araújo (2013) adaptado por Rodrigues, 2015.

Conforme se pode observar, destacam-se as atividades de educação ambiental desenvolvidas em UCs e áreas naturais, como passeios e trilhas. É importante destacar que duas dessas atividades mencionam explicitamente 0 trabalho envolvendo os aspectos naturais e históricos do ambiente. Destaca-se ainda que em uma das atividades a escola trabalhou com alunos portadores de necessidades especiais, oportunizando o acesso deles a uma unidade de conservação que estava estruturada para recebê-los, realizando uma atividade de educação ambiental inclusiva.

Observa-se também que a temática lixo, envolvendo aspectos como coleta seletiva, reciclagem, reutilização e compostagem, aparece novamente como uma atividade de educação ambiental bastante trabalhada nas escolas. No entanto, uma dessas atividades chama a atenção, pois a escola trabalhou a questão do lixo no contexto de uma comunidade indígena. Os alunos tiveram a oportunidade de interação com os índios e sua cultura, além de perceber as diferenças com relação a hábitos de consumo e produção de lixo.

O III ECEA foi realizado nos dias 29, 30 e 31 de outubro de 2014 no centro de eventos da cidade de Piratuba/SC, sendo inscrito um total de 76 resumos, que ficaram assim distribuídos em cada eixo temático: eixo I, sete trabalhos; eixo II, 20; eixo III, 11; eixo IV, 16; eixo V, 11; e eixo VI, nove trabalhos. (SANTA CATARINA, 2015d). Ressalta-se que em dois resumos não foi possível a identificação dos eixos temáticos e também o fato de que não houve resumos inscritos no eixo temático VII. Observa-se novamente maior 
volume de resumos inscritos no eixo II, com um total de 20 trabalhos, dos quais 17 se referem a atividades de estudos, pesquisas e experimentações desenvolvidas no âmbito formal de ensino, envolvendo os alunos.

Cabe destacar que, em virtude da não disponibilização dos anais do III ECEA, impossibilitando o acesso aos resumos inscritos, as informações foram obtidas por meio de uma planilha dos trabalhos inscritos, divulgada no endereço eletrônico da Secretaria de Estado do Desenvolvimento Econômico Sustentável - SDS. Assim, não foi possível identificar a temática de muitos trabalhos inscritos, bem como obter mais informações sobre estes.

De acordo com o documento da Secretaria de Estado do Desenvolvimento Econômico Sustentável (SANTA CATARINA, 2015d) serão apresentados na tabela 6 a seguir os temas referentes aos 17 resumos inscritos no eixo II que se referem a atividades de educação ambiental desenvolvidas nas escolas.

Tabela 6 - Temas das atividades de EA desenvolvidas nas escolas apresentadas no III ECEA/2014

\begin{tabular}{l|c}
\hline \multicolumn{1}{c|}{ Tema } & Quantidade \\
\hline Temas não identificados & 9 \\
Importância da água & 2 \\
EA e consumo de energia elétrica & 1 \\
Horto florestal na escola & 1 \\
Gestão ambiental na escola & 1 \\
EA e agricultura familiar (agroturismo) & 1 \\
\hline Projeto Com-Vida na escola & 1 \\
Lixo e reciclagem & 1 \\
Total & $\mathbf{1 7}$ \\
\hline
\end{tabular}

Fonte: Santa Catarina (2015d), adaptado por Rodrigues, 2015.

As poucas informações disponibilizadas não permitem que se faça uma análise mais detalhada das atividades de educação ambiental apresentadas no III ECEA. Ressalta-se, contudo, o fato de que, pela primeira vez nos relatos inscritos no ECEA, foi mencionado um projeto oficial proposto pelo MEC para o desenvolvimento da educação ambiental nas escolas - o Projeto Com-Vidas (Comissão de Meio Ambiente e Qualidade de Vida na Escola), que está sendo desenvolvido por uma escola. 
AMBIENTE \& EDUCAÇÃo

ISSN- 1413-8638

E-ISSN - 2238-5533

v. 23 , n. 1, p. $140-160,2018$

\section{Considerações finais}

A partir do reconhecimento da importância da educação ambiental para o enfrentamento da crise ambiental verificada na Conferência de Estocolmo (1972), o sistema educacional ocupa posição de destaque, pois segundo Torales (2013) assume papel importante para promover consciência, sensibilidades e atitudes socioambientais responsáveis. A autora alerta que isso não significa que a escola deva se tornar a única instância responsável pela educação, mas, pelo fato de ser uma instituição que durante um período longo e considerável na vida das pessoas desenvolve uma prática educativa planejada e sistematizada, deve assumir o compromisso de introduzir e desenvolver a dimensão ambiental na formação dos alunos.

A inserção da educação ambiental na escola e no currículo de forma especial é delicada, uma vez que a realidade escolar se constitui num território próprio que tem suas características e particularidades advindas do próprio sistema de ensino, da cultura institucional e dos saberes dos professores. Comentando sobre essa realidade, Tozoni-Reis (2012, p. 277) afirma:

Dada a complexidade do papel do professor da educação básica no Brasil, consideremos um desafio objetivar a ação educativa num campo importante e desvalorizado da vida social - em especial na escola pública. Então, a inserção da EA na escola pública é um desafio tão complexo quanto o desafio de realizar uma educação pública de qualidade no contexto histórico, social, político e econômico da sociedade sob o modo capitalista de produção.

Loureiro (2008, p. 10), ao comentar as modalidades de educação ambiental desenvolvidas na escola, reveladas nos resultados das pesquisas mencionadas, também reflete sobre essa questão ao afirmar que "[...] encontramos também grupos protagonizando ações com clareza pedagógica e política das implicações de cada escolha, outras vezes não".

Diante da complexidade da realidade vivenciada em cada escola, não é incomum o desenvolvimento das mais diversas atividades consideradas de educação ambiental. A questão é que muitas atividades ditas de educação ambiental se resumem a ações isoladas e fragmentadas que não conseguem dar conta dos resultados esperados da educação ambiental. Sobre esse 
aspecto, Nascimento (2003, p. 55), analisando a realidade da educação ambiental desenvolvida no município de Florianópolis (SC), comenta:

[...] no Brasil, como também em Florianópolis, o modelo de implementação da EA para a sustentabilidade tem ocorrido de forma desarticulada, isolada e direcionada para uma minoria, que não se reflete para toda a sociedade, nem muda o comportamento das pessoas.

É importante destacar que a realidade vivida pelo professor na escola pública em nada favorece a qualidade das atividades de ensino, incluindo as de educação ambiental. É sabido que os professores, na sua grande maioria, além de não terem acesso às condições estruturais mínimas necessárias para o bom desempenho das atividades de ensino, ainda possuem uma carga horária excessiva, não dispondo do tempo necessário para o planejamento de suas atividades; convivem com salas de aulas superlotadas e, como se não bastasse, são desestimulados e desprestigiados pelas remunerações aviltantes.

Além de os aspectos abordados se constituírem em uma realidade complexa, problemática e desafiadora para os professores, Leme (2012, p. 88) chama a atenção para outro aspecto igualmente importante da realidade do trabalho docente, que diz respeito a sua qualificação: "[...] muitos professores nunca tiveram oportunidade de estudar os referenciais teóricos da $E A$, não conhecem sua história, seus objetivos e princípios".

Lima (2011) também lembra que não é simples nem fácil realizar mudanças estruturais na escola. Essa dificuldade, segundo o autor, deve-se a concepções e práticas epistemológicas e pedagógicas consolidadas historicamente e como consequência do longo processo de abandono da educação na sociedade. O autor acrescenta ainda como agravantes dessa situação aspectos como a postura individualista e pouco democrática de muitos professores.

Poderíamos acrescentar também as dificuldades dos professores de trabalhar em equipe, bem como de reconhecer suas limitações e fragilidades epistemológicas e pedagógicas diante dos seus pares. Parece haver uma espécie de temor de que a necessária humildade pedagógica para a realização de processos pedagógicos interdisciplinares ou coletivos (como no caso da 
educação ambiental) seja confundida com incompetência ou falta de "autoridade pedagógica".

Por fim, com relação aos resultados das pesquisas apresentadas neste artigo, pode-se afirmar que, a sua disseminação e quase universalização no sistema educacional formal em Santa Catarina são uma boa notícia, que traz, porém, o grande desafio de qualificar a sua inserção e garantir a sua efetividade na escola. Somente assim a educação ambiental poderá de fato cumprir com os seus objetivos e contribuir para o enfrentamento e a superação da grave crise ambiental contemporânea.

\section{Referências Bibliográficas}

ARAÚJO, Marli Carvalho de. Educação Ambiental e Políticas Públicas em Santa Catarina: os casos dos I e II Encontros Catarinenses de Educação Ambiental. Monografia (Bacharel em Geografia). UFSC, Florianópolis/SC, 2013.

BRASIL. Ministério do Meio Ambiente. Secretaria Executiva. Diretoria de Educação Ambiental. Enraizamento da Educação Ambiental para um País de Todos. Educação Ambiental 2003/2006. Brasília, DF, 2006.

BRASIL. Educação na diversidade: o que fazem as escolas que dizem que fazem educação ambiental. TRAJBER; MENDONÇA (orgs.). Brasília: Secretaria de Educação Continuada, Alfabetização e Diversidade, 2007.

CARVALHO, Isabel Cristina de Moura. A educação ambiental no Brasil. In: Salto para o futuro: educação ambiental no Brasil - TV escola, Secretaria de Educação a Distância, MEC/BRASIL, Ano XVIII, boletim 01, mar. 2008.

DAHMER, Roseli Lídia. Ações pedagógicas e questões ambientais nas escolas de educação básica da rede pública estadual do município de Blumenau-SC. Dissertação (mestrado). PPGGEO/CFH/UFSC, Florianópolis, 2014.

FBCN/CESP. Legislação de conservação da natureza. São Paulo, 1986. 
. Para onde vai a Educação Ambiental? O cenário político-ideológico da Educação Ambiental Brasileira e os desafios de uma agenda política crítica contra-hegemônica. Revista Contemporânea Educação, n. 14, ago./dez. 2012. em: <http://www.unemat.br/prppg/ppgca/docs2014/para_onde_vai_a_educacao_am biental_o_cenario.pdf>. Acesso em: 7 nov. 2015.

; LIMA, Gustavo Ferreira da Costa. Mapeando as macrotendências político-pedagógicas da educação ambiental contemporânea no Brasil. VI Encontro Pesquisa em Educação Ambiental: a Pesquisa em Educação Ambiental e a Pós-Graduação no Brasil. Ribeirão Preto, set. 2011. Disponível em: <http://www.icmbio.gov.br/educacaoambeintal>. Acesso em: 10 nov. 2015.

LARUS, Instituto. Disponível em: <http://www.larus.com.br/>. Acesso em: 14 nov. 2015.

LEME, Taciana Neto. Conhecimentos práticos dos professores e sua formação continuada: um caminho para a educação ambiental na escola. In: GUIMARÃES, Mauro (org.). Caminhos da educação ambiental: da forma à ação. 5. ed. Campinas, SP: Papirus, 2012 (Coleção Papirus Educação).

LIMA, Gustavo Ferreira da Costa. Educação ambiental no Brasil: formação, identidades e desafios. Campinas, SP: Papirus, 2011 (Coleção Papirus Educação).

LOUREIRO, Carlos Frederico B. Prefácio. In: RORDIGUES, Angélica Cosenza. A educação ambiental e o fazer interdisciplinar na escola. Araraquara, SP: Junqueira \& Marin; Juiz de Fora, MG: FAPEB, 2008.

MATER NATURA - Instituto de Estudos Ambientais. Disponível em: <http://www.maternatura.org.br/prev/asp/detalhes.asp?id=BR-021>. Acesso em: 14 nov. 2015. 
NASCIMENTO, Rosemy da Silva. Instrumentos para prática de Educação Ambiental Formal com foco nos recursos hídricos. Tese (Doutorado em Geografia). PPGGEO/CFH/UFSC, Florianópolis, SC, 2003.

PEDRINI, Alexandre de Gusmão. Trajetórias da educação ambiental. In: BARCELOS, Valdo. Educação ambiental: reflexões e práticas contemporâneas. PEDRINI, Alexandre de Gusmão (org.). 6. ed. Petrópolis, RJ: Vozes, 2008. (Coleção Educação Ambiental).

SANTA CATARINA. Secretaria de Estado da Educação e do Desporto. Proposta Curricular de Santa Catarina. Educação Infantil, Ensino Fundamental e Médio: Temas Multidisciplinares. Florianópolis: COGEN, 1998. Agenda 21 Catarinense. O desenvolvimento sustentável em Santa Catarina. Governo do Estado de Santa Catarina, Florianópolis, 2004. Disponível em: <http://srv2.lemig.umontreal.ca/donnees/Projet\%20Bresil/dados/2\%20sc/agend a\%2021\%20sc.pdf>. Acesso em: 16 nov. 2015.

Decreto n. 3.438, de 5 de agosto de 2010. Aprova o Regimento Interno da Comissão Interinstitucional de Educação Ambiental do Estado de Santa Catarina. Florianópolis, SC, 2010. Disponível em: <http://server03.pge.sc.gov.br/LegislacaoEstadual/2010/003438-005-0-2010004.htm>. Acesso em: 14 nov. 2015.

. Secretaria de Estado do Desenvolvimento Econômico Sustentável.

Disponível em: <http://educacaoambiental.sds.sc.gov.br/index.php/instituicao/76-reasul>. Acesso em: 8 nov. 2015a.

Secretaria de Estado do Desenvolvimento Econômico Sustentável. Disponível em: <http://educacaoambiental.sds.sc.gov.br/index.php/quemsomos>. Acesso em: 10 nov. 2015b.

Secretaria de Estado do Desenvolvimento Econômico Sustentável. Disponível em: <http://www.sds.sc.gov.br/index.php/biblioteca/pastas- 
tematicas/meio-ambiente/educacao-ambiental/279-iii-ecea/file>. Acesso em: 17 nov. 2015c.

. Secretaria de Estado do Desenvolvimento Econômico Sustentável.

Disponível em: <http://www.sds.sc.gov.br/index.php/biblioteca/pastastematicas/meio-ambiente/educacao-ambiental/283-resumo-aprovados>.

Acesso em: 17 nov. 2015d.

TORALES, Marília Andrade. A inserção da educação ambiental nos currículos escolares e o papel dos professores: da ação escolar a ação educativocomunitária como compromisso político-ideológico. Revista Eletrônica do Mestrado em Educação Ambiental. Universidade Federal do Rio Grande, 2013. Disponível em: <http://www.seer.furg.br/remea/article/view/3437/2064> Acesso em: 11 nov. 2015.

TOZONI-REIS, Marília Freitas de Campos. Educação ambiental na escola básica: sobre a prática dos professores. Revista Contemporânea de Educação, vol. 7, n. 14, ago./dez. 2012. Disponível em: $<$ https://revistas.ufrj.brindex.php/rce/article/viewFile/1670/1519>. Acesso em: 10 nov. 2015. 